\title{
Aggressive Vertebral Hemangioma about a Case in Lomé
}

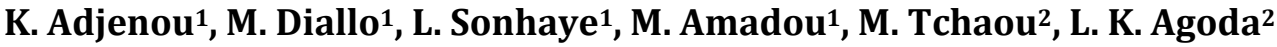 \\ ${ }^{1}$ Radiology and Medical Imaging Department of the CHU Campus, Lomé, Togo \\ ${ }^{2}$ Radiology and Medical Imaging Department of the CHU Sylvanus Olympio, Lomé, Togo \\ Email: mamadiallo126@yahoo.fr
}

How to cite this paper: Adjenou, K., Diallo, M., Sonhaye, L., Tchaou, M., Amadou, M. and Agoda, L.K. (2019) Aggressive Vertebral Hemangioma about a Case in Lomé. Open Access Library Journal, 6: e5766. https://doi.org/10.4236/oalib.1105766

Received: September 5, 2019

Accepted: October 26, 2019

Published: October 29, 2019

Copyright (C) 2019 by author(s) and Open Access Library Inc.

This work is licensed under the Creative Commons Attribution International License (CC BY 4.0).

http://creativecommons.org/licenses/by/4.0/

\begin{abstract}
Vertebral hemangiomas are benign tumour and are rarely symptomatic. Aggressive forms represent less than $1 \%$ of all cases. Medical imaging allows both diagnosis and evaluation of their aggressivity. To assess the role of radiology, embolisation, percutaneous vertebroplasty and surgery in the diagnosis and treatment of vertebral hemangiomas, we report our experience of one patient who had an age of 13 years. She presented with progressive medullary compression and is investigated with CT and MRI. The vertebral hemangioma is located in the lumbar spine at L3. Lumbar CT scan and MRI were done. In the CT scan we noticed L3 vertebral body and posterior arc destruction associated with hind sliding of L2 on L3. These lesions are associated with a significant infiltration of peri-vertebral soft tissues and dural sheath with heterogenous enhancement. The patient has embolised before surgery.
\end{abstract}

\section{Subject Areas}

Hematology

\section{Keywords}

Angioma, Aggressive, Vertebra

\section{Introduction}

Vertebral angiomas are benign tumours of malformative origin, consisting of neoformed blood vessels of normal structure, without arteriovenous shunt. These lesions represent $50 \%$ of benign spinal tumours [1] and according to Dahlin [2], $1 \%$ of primary bone tumours. They develop within the vertebra and modify it and can extend secondarily to the epidural space; their seat is usually dorsal. Their discovery is most often fortuitous. The majority of these lesions have no clinical 
translation and require no treatment. The progressive forms responsible for spinal cord compression are much rarer; they are part of neurosurgical management. We report our experience about an observation by emphasizing the role of imaging in assessing the degree of aggressiveness of the pathology.

\section{Patient and Observation}

A 13-year-old patient with no particular history, received in our department for a radiological check-up. The clinical examination revealed non-febrile lumbar pain, an insidiously installed motor deficit of the lower limbs that has gradually worsened over the past 6 months. The patient was investigated by CT followed by lumbar MRI. At the CT, we noted a destruction of the vertebral body and posterior arch of L3 associated with a backward shift from L2 to L3 (Figure 1). These lesions are associated with significant invasion of the peri-vertebral soft tissue and dural sheath with heterogeneous enhancement after injection of the iodized contrast agent (Figure 2).

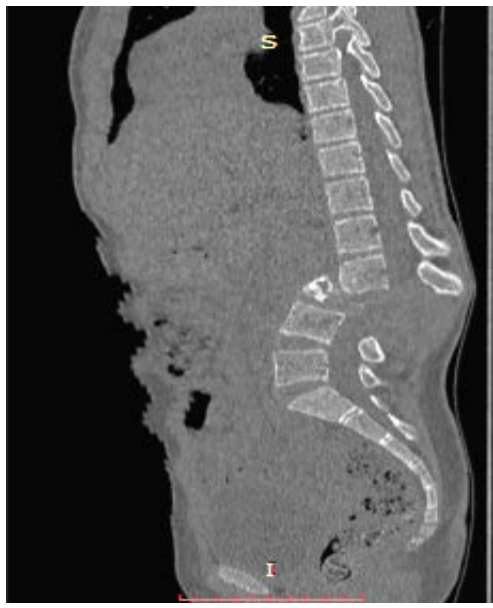

Figure 1. Sagittal reconstruction CT of the lumbar spine which shows a destruction of L3 with retro-listhesis of L2 sue L3.

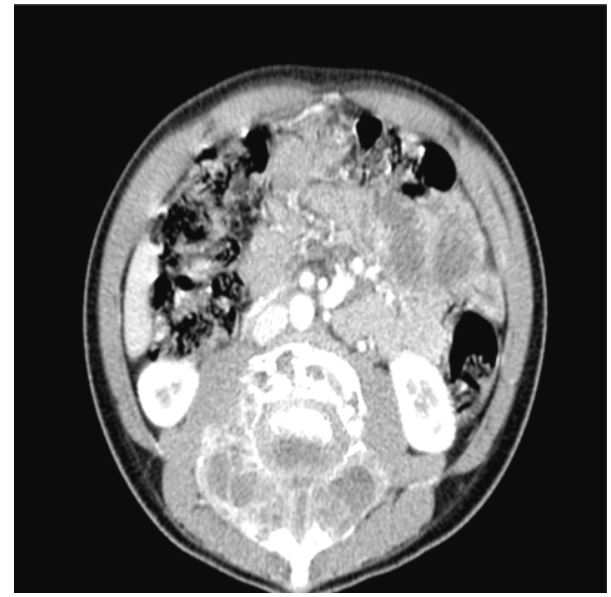

Figure 2. TDM axial section with PCI injection, showing flooding of the vertebral peri-peri soft tissue that rises heterogeneously after PC injection. 
On MRI, it is objectified an almost complete collapse of the L3 vertebra with a multi-loculated anterior residual part (Figure 3 \& Figure 4). The contents of this vertebrae protrude posteriorly occupying the central lumbar canal and the pediculo-lamar space. This heterogeneous formation is in hypo-signal $\mathrm{T} 1$ (Figure 3), hyper-signal partly T2 (Figure 4) and is partially enhanced on the injected series (Figure 5). Histologically, the section designs examined under a healthy epidermis show a clearly benign tumor proliferation made of anastomosed vascular sales with regular papillary projections bordered by cells without cytonuclear atypia of malignancy noted. Mitosis is very low, estimated at 1 in 10 fields at high magnification. There are no foci of necrosis on the tumor surface. This aspect suggested a hemangioma. The patient received preoperative embolization supplemented by vertebroplasty. The post-therapeutic evolution has been marked by a progressive improvement in neurological symptomatology. The patient is followed on an outpatient basis per month, without however resuming studies.

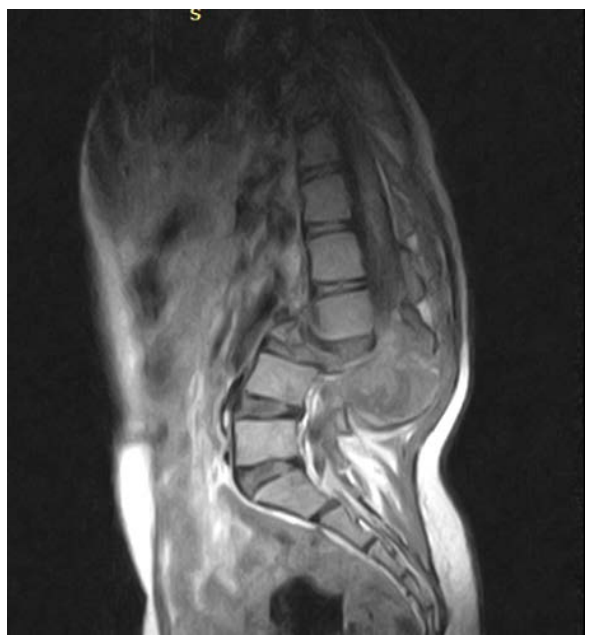

Figure 3. Sagittal sequence in T1 with an almost complete collapse of the L3 vertebra with invasion of the soft tissues in hypo-signal T1.

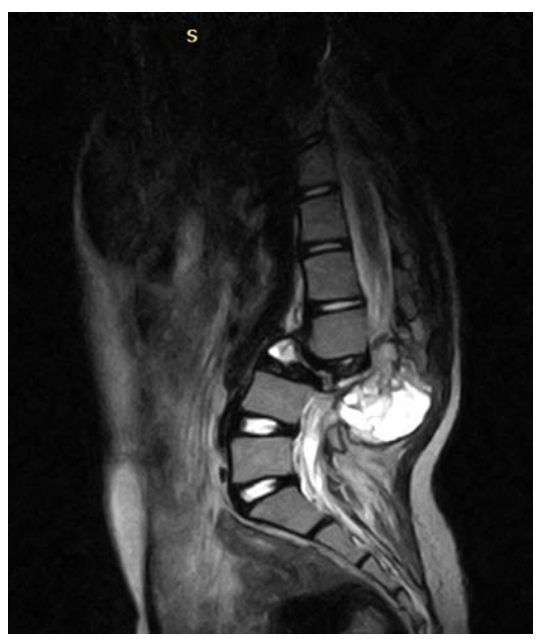

Figure 4. T2 sagittal sequence, objectivizing the almost complete collapse of the L3 vertebra with a residual anterior part and the invasion of the soft parts in hyper-signal T2. 


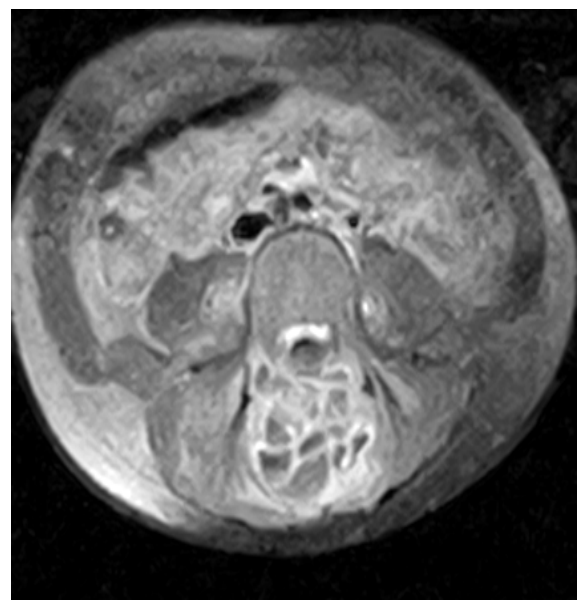

Figure 5. T1 axial sequence with Gado showing a heterogeneous enhancement of soft tissue flooding.

\section{Discussion}

The vertebral hemangiomas represent $50 \%$ of the benign tumors and according to Dahlin [3], 1\% of the primary bone tumors. Aggressive vertebral hemangiomas are rare [4]. HV can affect all age groups [5]. This lesion is rare in children [6] or even exceptional before the age of 10 years. However, our patient's age was 13 years. A predominance in young adults, with a discrete female predominance, two women to one man has been reported [7]. Its incidence increases gradually with age [8]. It is usually found in middle-aged adults between the fourth and fifth decade; about one-third of the lesions are revealed in the fifth decade [9]. In our case, the site of the lesion was rather lumbar (L3) unlike the one whose dorsal location is most frequent from T3 to T9 [5]. Cervical localization has rarely been described in the literature [5] [7]. As for HV compressive, they are located in $90 \%$ of cases at the level of the backbone and more precisely between T3 and T9. The attack is in single rule: this is seen in $75 \%$ of cases [10], as in our observation. Clinical symptomatology is most often represented by spinal cord compression. This was noted in our patient. It is more rarely manifested by back pain or radiculalgia [1]. The pathophysiology of neurological signs involves several parameters. In general, this is an epidural extension as we noted in our observation. On the other hand, vertebral compression or compressive haematomas rarely occur [1]. Concentric bone hypertrophy can be involved in the genesis of symptomatology [5]. Aggressive vertebral hemangioma has a typical appearance on standard radiographs [2]. It sits on the vertebral body, which is demineralized and has vertical spans, creating the characteristic grid appearance that is lost in places. In rare cases, it is a spindle-shaped appearance indicating an extension towards the soft para-vertebral tissues. The CT study, when the appearance is not typical, makes it possible to specify the extent of bone damage (pedicles, posterior arch), epidural extension, hyper-vascularization and tissue stroma of the lesion [1] [11].

On MRI, the aggressive angioma has a hyposignalT1 and a hypersignal T2 due 
to its vascular content, unlike most asymptomatic angiomas which have a fat content in hypersignal T1 and T2 [12]. MRI also makes it possible to look for the posterior arch and possible spinal cord compression as in our case. The diagnosis of certainty is based on histological examination. Vertebroplasty is a good treatment for hemangiomas leading to a painful spinal syndrome [13]. while compression angioma treatment consists of surgical decompression, often preceded by selective arterial embolization [14].

\section{Conclusion}

Symptomatic vertebral hemangioma with neurological disorders is rare. The diagnosis must be made early and based on imaging, which allows for accurate lesion assessment and histological examination. The objective of the treatment is twofold, to provide spinal cord decompression and to treat symptomatic angioma.

\section{Conflicts of Interest}

The authors declare no conflicts of interest regarding the publication of this paper.

\section{References}

[1] Deramond, H., Darasson, R. and Galibert, P. (1989) Percutaneous Vertebroplasty with Acryliccement in the Treatment of Aggressive Spinal Angiomas. Rachis, 1, 143-153.

[2] Chagon, S., Vallee, C., Blery, M. and Chevrot, A. (1992) Hémangiome et hémangiomatose diffuse; Editions Techniques Encycl. Med. Chir., Radiodiagnostic Neuroradiologie. Appareil Locomoteur 3-1489-A-10, 11 p.

[3] Chagon, S., Vallee, C., Blery, M. and Chevrot, A. (1992) Hemangioma and Diffuse Angiomatosis. Encyclopédie médicochirurgicale, 31489, 1-11.

[4] Lee, S. and Hadlow, A.T. (1999) Extraosseous Extension of Vertebral Hemangioma: A Rare Cause of Spinal Cord Compression. Spine, 24, 2111-2114. https://doi.org/10.1097/00007632-199910150-00009

[5] Ben Hamouda, I., Tougourti, M.N., Chiraz, A., Dorsaf, M., Hassen, Z. and Mohsen, H. (1999) Compressive Vertebral Angiomas: A Case Report. La Tunisie Médicale, 77, 236-241.

[6] Bassou, D., Darbi, A., Benaissa, L., El Khyari, A., Chaouir, S., Benameur, M. and El Kharras, A. (2008) L'hémangiome vertébral: Une cause rare de compression médullaire chez l'enfant. Journal of Radiology, 89, 262-263. https://doi.org/10.1016/S0221-0363(08)70404-9

[7] Laredo, J.D., Reizine, D., Bard, M. and Merland, J.J. (1986) Vertebral Hemangioma, Radiologic Evaluation. Radiology, 161, 183-189. https://doi.org/10.1148/radiology.161.1.3763864

[8] Danielle, H., Guy, C. and Thierry, D. (2004) Long-Term (6-Year) Follow-Up of Untreated Multiple Aggressive Vertebral Haemangiomas in an Adolescent. Pediatric Radiology, 34, 831-832. https://doi.org/10.1007/s00247-004-1290-9

[9] Chen, H.I., Heuer, G.G., Zaghloul, K., Simon, S.L., Weigele, J.B. and Grady, M.S. (2007) Lumbar Vertebral Hemangioma Presenting with the Acute Onset of Neurological Symptoms. Neurosurgery. Spine, 7, 80-85. 
https://doi.org/10.3171/SPI-07/07/080

[10] Ross, J.S., Masaryk, T.J., Modic, M.T., Carter, J.R., Mapstone, T. and Dengel, F.H. (1987) Vertebral Hemangioma: Magnetic Resonance Imaging. Radiology, 165, 165-169. https://doi.org/10.1148/radiology.165.1.3628764

[11] Griffith, J.F. and Kumta, S.M. (1997) Clinics in Diagnostic Imaging. Aggressive Vertebral Hemangioma. Singapore Medical Journal, 38, 226-230.

[12] Tamraz, J.C. (2000) Imagerie par Résonance Magnétiquede la tête et du rachis-atlas. Didactique et guide d'interprétation. Springer-Verlag France, Paris, 286.

[13] Chiras, J., Barragán-Campos, H.M., Cormier, E., Jean, B., Rose, M. and Le Jean, L. (2007) Vertébroplastie: État de l'art. Journal of Radiology, 88, 1255-1260. https://doi.org/10.1016/S0221-0363(07)91335-9

[14] Shah, K.C. and Chacko, A.G. (2004) Extensive Vertebral Haemangioma with Cord Compression in Two Patients: Review of the Literature. British Journal of Neurosurgery, 18, 250-252. https://doi.org/10.1080/02688690410001732689 